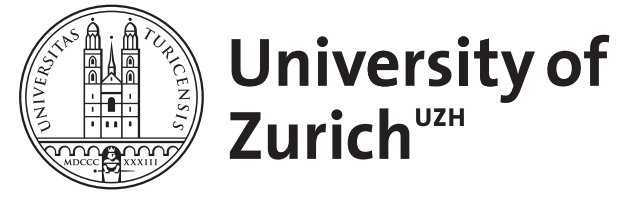
Archive

University of Zurich

University Library

Strickhofstrasse 39

CH-8057 Zurich

www.zora.uzh.ch

Year: 2019

\title{
Corporate responsibilization
}

Mildenberger, Carl David

DOI: https://doi.org/10.1111/japp.12290

Posted at the Zurich Open Repository and Archive, University of Zurich

ZORA URL: https://doi.org/10.5167/uzh-191830

Journal Article

Published Version

\section{(c) 980}

The following work is licensed under a Creative Commons: Attribution-NonCommercial-NoDerivatives 4.0 International (CC BY-NC-ND 4.0) License.

Originally published at:

Mildenberger, Carl David (2019). Corporate responsibilization. Journal of Applied Philosophy, 36(1):93107.

DOI: https://doi.org/10.1111/japp.12290 
fournal of Applied Philosophy, Vol. 36, No. 1, February 2019

doi: 10.1111/japp.12290

\section{Corporate Responsibilization}

\section{CARL DAVID MILDENBERGER}

ABSTRACT This article examines the conditions for responsibilizing corporations. When we responsibilize an agent, we hold him responsible for his choices - although we are aware that he is not yet fully fit to be held responsible - in order to induce in him the relevant characteristics for being fit to be held responsible at a later time. I find that the conditions of responsibilizability are not identical to the conditions for responsibilization we usually and reasonably apply. Typically, we only responsibilize agents who do not only meet the comparably weak conditions of responsibilizability, but who also fulfil additional criteria, as for example having demonstrated first signs of normative reasoning. I argue that corporations do not only meet the minimum threshold of responsibilizability, but also a comparably higher threshold, which allows us to engage in particularly effective forms of responsibilization. Basically, we may permissibly responsibilize the overwhelming majority of corporations in the same way parents responsibilize their growing children.

\section{Introduction}

This article examines the conditions for responsibilizing corporations. When we responsibilize an agent, we hold him responsible for his actions - i.e. we praise or blame him - although we are aware that he is not yet fully fit to be held responsible. ${ }^{1}$ Although holding him responsible might not be appropriate strictly speaking, the rationale is a developmental one. We hope that our holding him responsible will induce in him the self-awareness and self-regulation required for being fully fit to be held responsible at a later point in time. ${ }^{2}$ The typical example for this practice is that of parents responsibilizing their children.

Pettit suggests that we should not only responsibilize children (i.e. individual agents), but also group agents. This is because a world in which more group agents are fit to be held responsible seems to be a more just one. Think of the otherwise apparent deficits of responsibility, i.e. cases in which no individual agent is fit to be held responsible, but a grave harm follows from the actions of a group agent. ${ }^{3}$ However, although Pettit presents an account of holding corporations responsible, he does not develop an account of responsibilizing corporations. This is what I shall provide here. ${ }^{4}$ Note that my question here is not that of whether we should responsibilize group agents. I follow Pettit in that doing so generally speaking is desirable. ${ }^{5}$ Instead, I focus on the conditions of when we may responsibilize.

From an applied perspective, the question of when we may responsibilize corporations is as important as the question of when they are fit to be held responsible. This is because: 
$[w]$ e are naturally disposed to ascribe responsibility ... not just to responsible agents and agencies but also to 'responsibilizable' entities - not just to agents that are fit to be held responsible but also to entities that are capable of being made fit to be held responsible. ${ }^{6}$

Importantly, even people who deny that commercial corporations are fit to be held responsible might admit that they are responsibilizable, and thus consent to acts of responsibilization. In this sense an account of corporate responsibilization provides us with new tools to fight deficits of responsibility even critics of full-blown corporate responsibility can endorse.

I shall first outline how we may derive conditions of responsibilizability from conditions of being fit to be held responsible - and how the former are not identical to conditions for responsibilization (Section 2). I will then present an intuitive account of conditions for responsibilization, relying on the example of parents responsibilizing their children (Section 3). Roughly speaking, the respective conditions are that an agent faces a normatively significant choice, that he has genuinely acted in the positive domain before, and that he has shown first signs of normative judgment. Section 4 examines whether these conditions are not only intuitive but also normatively appropriate. Notably, it examines whether the threshold they establish is neither too low (with the danger of responsibilizing unfit beings) nor too high (with the danger of not allowing us to responsibilize those group agents involved in deficits of responsibility). I will argue that we may permissibly lower the intuitive threshold, but that this comes at the cost of us being less able to effectively responsibilize group agents. In Section 5 I conclude that, in fact, virtually all corporations meet the (comparatively high) intuitive threshold. This means that we may permissibly responsibilize them in rather extensive and particularly effective ways - just like parents responsibilize their children.

\section{Responsibility, Responsibilizability, and Responsibilization}

According to List and Pettit, there are three conditions of fitness for individual and group agents alike to be held responsible. ${ }^{7}$

Normative Significance

Normative Judgmental Capacity ${ }^{8}$

Relevant Control
The agent faces a normatively significant choice, involving the possibility of doing something good or bad, right or wrong.

The agent has the understanding and access to evidence required for making normative judgments about the options.

The agent has the control required for choosing between the options.

List and Pettit argue that these conditions are individually necessary for responsibility. Without normatively significant choices, no questions of moral responsibility arise. Without the agent being able to make normative judgments, e.g. because he is entirely unaware of morally salient evidence, there is no basis for holding the agent fully responsible. Finally, if an agent cannot control his choices, e.g. when somebody else uses his hand against his will to pull a trigger, there will always be a full or partial 
excuse for the agent. It is important that List and Pettit are not merely concerned with holding agents causally responsible, with holding them accountable, or with thinking them responsible. They argue that these conditions are jointly sufficient for holding an agent morally responsible - i.e. they justify corrective actions. ${ }^{9}$

Let us call the threshold these three conditions jointly establish the responsibility threshold. If an agent fulfils all three conditions, then he can be held fully responsible for his choice. If he only fulfils one or more of these conditions to a lesser degree say he is intoxicated - then we may still hold the agent partially responsible for his choice.

In dependence on List and Pettit's three conditions and Pettit's idea that being responsibilizable means 'being capable of being made fit to be held responsible' we can come up with three corresponding conditions of responsibilizability. ${ }^{10}$

Potential Occasion

The entity might face a normatively significant choice, involving the possibility of doing something good or bad, right or wrong.

Normative Judgmental Capability The entity is capable of having the understanding and access to evidence required for making normative judgments about the options.

Capability of Control

The entity is capable of having the control required for choosing between the options.

Taken together, these three conditions provide us with a responsibilizability threshold. In contrast to the responsibility threshold (which gives us minimum requirements for when an agent is fit to be held responsible) the responsibilizability threshold tells us the minimum requirements for when a being is responsibilizable, i.e. capable of being made fit to be held responsible.

If, for instance, a certain entity were never capable of controlling its choice between right and wrong then that entity would not be responsibilizable. A concrete singular and limited (i.e. situation-specific) case might be a severely paralysed person on her own never being able to pull the lever when faced with trolley scenarios. Such a person is not responsibilizable with respect to trolley scenarios, as CAPABILITY OF CONTROL is violated. Basically, as Potential Occasion, Normative Judgmental Capability, and Capability of Control are more encompassing versions of Normative Significance, Normative Judgmental Capacity, and Relevant Control respectively, if one of the former three conditions is permanently violated, then that entity can never fit to be held responsible and thus never capable of being made fit to be held responsible strictly speaking.

Here is a complication. It seems that we can responsibilize a being even if it is not responsibilizable. Note that whereas responsibilizability refers to an entity's theoretical capability of being made fit to be held responsible, responsibilization refers to concrete acts of responsibilizing beings. Following List and Pettit's definition, to responsibilize an agent is to hold him responsible, e.g. by blaming him, although he is not fully fit to be held responsible, with the aim of making him fit to be held responsible. ${ }^{11}$ This means that whether we are successful, in the sense of achieving our developmental goal, does not affect whether we are engaging in responsibilization. In fact, being unsuccessful seems to be the exception rather than the rule for most of our acts of responsibilizing children. 
There are different reasons for why we might be unsuccessful. One possibility simply is that we are very bad at responsibilizing. Another possibility is that we aim at the wrong target. The 'normal' case of responsibilization is that a prima facie suitable target, which is not fully fit to be held responsible yet, is not fully fit to be held responsible because it meets the responsibilizability threshold but not yet the responsibility threshold. But conceptually speaking there is nothing which prevents us from responsibilizing a being whose not-being-fully-fit-to-be-held-responsible actually comes down to it not being responsibilizable at all. In such cases, it would be unreasonable to responsibilize if we are aware of this. But sometimes we might not know (or ignore) that a certain entity is not responsibilizable, and proceed to engage in all the usual concrete actions necessary to responsibilize without much ado.

For example, we may proceed to try to responsibilize raccoons. After all, a raccoon is an agent for List and Pettit, as it possesses representational states that depict how the world is, motivational states that specify how it wants the world to be, as well as a limited capacity to change the world according to its desires. ${ }^{12}$ Or we may proceed to responsibilize the severely paralysed person with respect to trolley scenarios by repeatedly confronting her with trolley scenarios and levers to pull. To be sure, our efforts of responsibilization would not be successful, as far as we know, with respect to the raccoons. And they would not be successful and probably wrong (because of being cruel) with respect to the paralysed person. But we might still choose to responsibilize in these situations; especially if we are not sure whether we might succeed. As our efforts of responsibilization aim at beings which do not (fully) meet at least one of the conditions of the responsibility threshold, it might all too easily happen that we responsibilize a being which does not even meet the conditions of the responsibilizability threshold. To summarise, we can engage in responsibilization somewhat independently of responsibilizability.

As responsibilizability and responsibilization can come apart, so can the respective conditions. In practice, they seem to deviate quite substantially. On the one hand, most people would probably agree that it is at least unreasonable, most likely inappropriate, and potentially cruel or otherwise wrong to responsibilize non-responsibilizable beings of which we know they are non-responsibilizable. Imagine what it would be like for a severely paralysed person (say she is a convinced consequentialist) to repeatedly get confronted with the classic trolley scenario and a lever to pull - and to be blamed for her inaction. So, one intuitive condition for permissibly responsibilizing entities seems to be to only target responsibilizable entities. In this respect, responsibilizability and legitimate responsibilization are linked.

On the other hand, it seems that we typically do not start to responsibilize entities until they fulfil considerably more demanding conditions than those of responsibilizability. Consider that virtually all newborns are responsibilizable. Yet we do not start to responsibilize them right away. Given what has been said, it does not look like responsibilizing them prior to a certain age would be impossible or impermissible. But for some reasons it strikes us as plausible to require more than mere responsibilizability before we engage in responsibilization. So what are good conditions for responsibilization and how do they differ from conditions of responsibilizability? 


\section{An Intuitive Responsibilization Threshold}

The following strikes me as an empirically relevant threshold for responsibilization, i.e. as one actually used by many parents in deciding when to responsibilize their children.

Normative Significance

Positive Evidence

Normative Evidence
The child faces a normatively significant choice, involving the possibility of doing something good or bad, right or wrong. We have experienced the child choosing responsibly in the positive domain.

The child has demonstrated first signs of satisfying Normative Judgmental CAPACITY (though not necessarily in the same context as that of the normatively significant choice it now faces).

I shall refer to the threshold jointly constituted by these three conditions as the intuitive responsibilization threshold. What I mean if I say that we have experienced the child 'choosing responsibly in the positive domain' is that there is evidence that the child has satisfied the positive counterparts of Normative Significance and Normative Judgmental Capacity as well as Relevant Control at some point and has acted accordingly. Spelling out these positive counterparts of Normative Significance and Normative Judgmental Capacity we get:

Positive Significance

Positive Judgmental Capacity
The agent faces a significant choice involving only positive options.

The agent has the understanding and access to evidence required for making positive judgments about the options. ${ }^{13}$

To satisfy Positive Evidence it is not necessary that the child (partially) satisfies Positive Judgmental Capacity and Relevant Control at the time of the normatively significant choice. It is enough that we have evidence that it has satisfied these conditions before. Likewise, in order to satisfy Normative EvidEnCE, the child does not have to (partially) satisfy Normative Judgmental CAPACiTy at the time of the normatively significant choice. As the very point of responsibilization often is to make the target fulfil Normative Judgmental Capacity and Relevant Control (more often), naturally NoRMATIVE EvidENCE does not presuppose (partial) fulfilment of these conditions at the time of the choice.

An example might help to clarify. A four-year-old boy regularly eats spaghetti Bolognese. At some point, his parents encourage him to try some Parmesan on top. As it turns out, the boy likes it. Whenever he is presented with the choice of adding Parmesan - say a bowl with grated Parmesan is placed on the table in front of him he proceeds to take loads, because 'that's the way I like it best'. One day the boy returns from nursery and tells the following story. 'Today it was spaghetti Bolognese for lunch, and they even had Parmesan. But I only took a little. Otherwise there would not have been anything left for the others.'

In this case, the boy satisfies Positive Evidence. Notably his recurring choices to take Parmesan from the bowl placed in front of him in accordance with his preferences make him fulfil this condition. He also satisfies Normative Evidence, as he has just 
shown first signs of being able to handle normative reasons. So, when now an occasion for responsibilization arises, then according to the suggested conditions the parents may hold their son responsible although he is not yet fully fit to be held responsible, i.e. responsibilize him. For instance, the boy could face the choice of whether to make sure his little brother does not run on the street - as he was told to by his father who quickly needs to get inside - when he would actually prefer to stalk the cat appearing on the other side of the street. If in this situation he chooses to go after the cat leaving his brother behind, then his parents may blame him for developmental reasons according to the suggested conditions. ${ }^{14}$

Note that the main difference between the responsibilizability threshold and the intuitive responsibilization threshold is the kind of evidence required. This makes intuitive sense. While the responsibilizability of an entity does not (and intuitively should not) depend on the kind of evidence we have, we only actually engage in responsibilization once we can be reasonably sure (based on some evidence we have) that we are not doing something wrong or ineffective.

\section{The Minimum Responsibilization Threshold}

In order to establish conditions for responsibilizing corporations we need to judge whether the suggested intuitive threshold is normatively appropriate, i.e. whether we may permissibly rely on it when engaging in acts of responsibilization. One thing which speaks in favour of the intuitive threshold is that it seems to be very robust. That is, if an agent meets the threshold, then seemingly little can go wrong in responsibilizing him.

First, the intuitive threshold seems to be normatively robust. It seems to be generally permissible to responsibilize agents who satisfy all conditions. Notably, by relying on the three conditions - i.e. by only targeting already well-developed agents - we are significantly reducing the risk of asking too much of the agent to be responsibilized or of responsibilizing non-responsibilizable agents. Second, the intuitive threshold is practically robust; relying on it promises that our efforts of responsibilization will be effective and efficient. Because there is a lot we can work with, notably the evidence of the agent's prior positive choices and the first signs of normative judgment, it seems that substantial further progress can be made in a very precise, purposeful way. For example, by relying on analogies, we can build on the positive choices the agent faced and on the normative reasons he already knows to further develop his normative powers of judgment. ${ }^{15}$ Or we can grant him normative control over situations he hitherto only positively controlled. Or we can precisely interfere in order to strengthen, weaken, or alter the agent's existing normative beliefs, i.e. what he thinks he knows about normative matters, if we see fit. Or we can work with a clear focus towards the agent having one particular normative insight we deem crucial. And so on.

On the other hand, one thing which speaks against the intuitive threshold is that it rests on what one may judge a dubious assumption. Namely, it relies on the idea of a two-stage development model of an agent's powers of judgment. It implicitly suggests that agents first acquire powers of judgment in the positive domain, before they also start to understand normative reasons; with acquiring the former being a crucial step for acquiring the latter. This assumption becomes apparent in that Positive Evidence calls 
for substantially developed positive judgmental capacities, whereas Normative EVIDENCE only calls for first signs of normative understanding.

The two-stage development model does not seem to be clearly wrong. First, children indeed seem to develop like this. Intuitively, they act like genuine agents, e.g. when building with bricks, before they first grasp normative concepts. ${ }^{16}$ Second, group agents may also develop like this. Imagine a corporation selling drinks which starts buying springs all around the world in order to cut production costs. Reorganising its supply chain in this way, the corporation clearly is an agent with respect to business matters. But it might only come to realise that privatising springs also has a normative dimension later, e.g. after the protests of locals against its business practices. Third, the fact that in order to acquire normative powers of judgment an agent needs to possess a metalanguage instead of merely an object-language speaks in favour of this development path. ${ }^{17}$ Individual and group agents must be able to form and understand statements like 'It is desirable that ...'. Fourth, while it is comparably easy to imagine beings which exclusively possess positive powers of judgment - as for example most animals - it is rather difficult to imagine beings acquiring positive and normative powers strictly simultaneously; let alone beings exclusively possessing normative powers of judgment. Still, the two-stage development model is an empirical assumption. As it might be refuted, relying on it is somewhat problematic.

Now, as important as the intuitive threshold's robustness and its implicit assumptions are, ultimately the question of whether it is normatively appropriate depends on whether the threshold is too high or too low. Responsibilizing beings which do not meet the conditions of fitness to be responsibilized is at the very least faulty - and probably wrong. Such undercutting of thresholds is particularly problematic as acts of responsibilization, even permissible ones, already constitute a transgression; an 'overstraining' of the targeted being, so to speak. Responsibilization inherently misallocates blame, as we are blaming beings which are not strictly blameworthy. We can justify this problematic practice in light of its developmental rationale. But if we actually responsibilized beings which are unfit to be responsibilized, then, over and above blaming beings which are not blameworthy, we would be blaming beings which are not even capable of being blameworthy.

On the other hand, if the threshold were too high, we would end up not really tackling the underlying problem of deficits of responsibility. If we considered too many agents to be unfit for being responsibilized, these deficits erroneously would prevail. Put differently, in order to tackle the problem of deficits of responsibility, ceteris paribus a lower threshold seems desirable.

As it stands, the intuitive threshold strikes me as rather demanding. That is, prima facie it seems to be too high rather than too low. Probably, this is because parents do not run into serious normative problems if they do not responsibilize their children as early as permissible. So, what I will do in the rest of this section is to check the individual conditions of the threshold in turn to see if they can permissibly be lowered. Like this, we can determine the minimum permissible responsibilization threshold. On its basis, we can be sure not to exclude too many corporations as legitimate targets for responsibilization.

As regards Normative Significance, there is not much leeway to lower the threshold. For unless the entity or agent faces a normatively significant choice, I cannot see how there could be legitimate responsibilization. Holding someone morally responsible 
for a purely positive choice cannot be right. ${ }^{18}$ It might be possible to hold agents responsible for their hypothetical normatively significant choices ('What would you do in a trolley scenario?'). But it is unclear to what extent altering NoRMATIVE SigNifICANCE in this respect would actually lead to a lower threshold. While it would relax the condition in the sense of allowing it to be fulfilled not only by actual but also by hypothetical choice situations, making use of this relaxation requires the agent to be able to imagine being in a normatively significant choice situation and to reach normative judgments in this hypothetical situation. This requires higher mental capabilities than facing actual choice situations.

Relaxing Positive Evidence and Normative Evidence is more promising. Basically, the role these conditions jointly play is to make sure there is evidence to the effect that we do not engage in responsibilizing beings which are unfit to be responsibilized. By requiring that the agent has satisfied Positive Significance, Positive Judgmental Capacity and Relevant Control before, and by requiring that the agent has shown first signs of being able to handle normative reason, it seems like we can be pretty sure not to wrongfully responsibilize an agent unfit to be responsibilized. That is Positive EvidenCE and Normative Evidence are partly motivated by a normative concern. But the way in which they fulfil this function may be criticized as unnecessarily demanding in various ways.

Consider Positive Evidence. First, it seems like we can unproblematically responsibilize beings which at some point have satisfied Positive Significance, Positive Judgmental Capacity, and Relevant Control, but which we have not experienced doing so. Although this means that we have to solve the epistemic problem of determining whether the being fulfilled these conditions, what counts from a normative perspective is not our having evidence, but that the being actually fulfilled them. Second, and more fundamentally, note that there is no necessary connection between having satisfied Positive Significance, Positive Judgmental Capacity, and Relevant Control before and being fit to be responsibilized now. That a being has (at least partially) satisfied these conditions certainly is an indication to this effect. But, for instance, an agent could have had an accident in the meantime, falling into a persistent vegetative state. Third, and even more fundamentally, what underlies Positive Evidence is the implicit assumption that prior actions in the positive domain are an indicator for the normative developmental status of the agent, i.e. the idea of a two-stage development model of an agent's powers of judgment. However, unless we subscribe to the twostage development model having satisfied Positive Significance, Positive Judgmental Capacity, and Relevant Control is not a necessary prerequisite for being fit to be responsibilized.

Consider Normative Evidence next. At least in some cases it does not seem like an agent first has to show some evidence of understanding normative reasons before we can permissibly responsibilize him. Consider the spaghetti case again. Intuitively, it would not be wrong to blame the boy for taking all of the Parmesan from the bowl when eating at home, even if he never uttered the statement revealing he knows about concerns of distributive justice.

First, this seems perfectly fine if the boy already fulfils Normative Judgmental CapaCITY partially, i.e. with respect to the relevant normative considerations for that case only, but simply has never openly demonstrated that he does. In that case, he even would be fully fit to be held responsible with respect to his choice of taking all of the Parmesan.

(C) Society for Applied Philosophy, 2017 
Second, even if he lacks the respective partial Normative Judgmental Capacity (and all other forms of Normative Judgmental Capacity) blaming him does not have to be wrong. For one could argue that holding him responsible although he possesses no Normative Judgmental Capacity as of yet is appropriate for the exact same reason all responsibilization is: because of a developmental rationale. Only that in a situation with an agent having no normative understanding whatsoever, responsibilization is not aiming at further developing his existing normative capacity, but at sparking a first idea that normative reasons exist and how they work. Cases in which it seems appropriate not to require any prior signs of normative understanding intuitively are those which are simple, in that one normative consideration clearly is the decisive one (e.g. distributive justice in the spaghetti case), and in which there is little at stake (unlike the watching-over-the-little-brother case).

Note one important consideration to support this argument for the legitimacy of responsibilizing agents with no normative understanding as of yet; namely that blaming an agent is not the same as punishing him. One might plausibly argue that it is never legitimate to punish agents with no normative understanding. Genuine incomprehension seems a perfectly good excuse when something bad is done. ${ }^{19}$ But although treating somebody as if he were responsible and thus blaming him - i.e. a very mild form of holding him responsible - is in itself a penalty, we have to distinguish between how far we hold someone responsible in light of what he did and, with a view to this responsibility, how much we want to punish him for that deed. ${ }^{20}$ Corrective actions in the course of responsibilization come in different degrees of harshness, with harsher methods (like punishment) being subject to additional conditions of legitimacy for that method. While it seems appropriate to blame the boy for taking all of the Parmesan, it would not be appropriate to punish him. The first is warranted by the developmental rationale of responsibilization (and the penalty aspect of blaming to be taken as a necessary evil). But the second is not warranted in case the boy does not understand the normative considerations tied to his actions. Without any normative understanding, there is no fault in the boy's behaviour and nothing that warrants punishment.

To summarise, there seems to be no general normative reason why we may not lower the threshold for responsibilization by weakening Positive EvidenCE and NormaTIVE EvidENCE. The most natural suggestion seems to be to simply replace these two with the plain normative desideratum we are concerned about. This yields the alternative, lower condition

RESPONSIBILIZATION FITNESS

The agent is fit to be responsibilized at the time of Normative Significance.

Given my preceding analysis, if spelt out ResPonsibILIZATION Fitness intuitively comes down to the agent fulfilling Normative Judgmental Capability and Capability of ConTROL at the time of being responsibilized. This is because efforts of responsibilization can aim both at increasing an agent's normative powers of judgment and at increasing his relevant control of the choice situation - potentially starting from zero capacity (but given capability) for either aspect. Likewise, they can proceed both by granting the agent the power to judge for himself and by granting him the relevant control - also potentially starting from zero. Normative Significance and Responsibilization Fitness jointly constitute the minimum responsibilization threshold. ${ }^{21}$ Now, before engaging with the case 
of responsibilizing corporations, it is important to notice that even if there seems to be no general reason why lowering the threshold for responsibilization would lead to a normatively inacceptable threshold, relaxing the respective conditions comes at a cost. There is a pro tanto reason which speaks against doing so; a side-effect of opting for a less demanding threshold in order to widen the circle of legitimate targets. Notably, at the same time that the circle of legitimate targets grows bigger, our toolbox of measures for legitimately responsibilizing agents becomes smaller.

This is best to be seen as regards the extent of legitimate punishment. While punishing an agent for his misbehaviour on top of blaming him is an option if the agent already demonstrated fully developed normative powers of judgment, and while punishing an agent with partially developed normative powers of judgment might be appropriate if the misbehaviour occurred within a normative context the agent already masters, punishing an agent not even partially satisfying Normative Judgmental CAPACITY would be wrong. Without any normative understanding, there is no fault that warrants punishment. Likewise, it would be wrong to punish an agent whose developmental status we do not know (as we no longer require Normative Evidence before engaging in responsibilization). The maxim in dubio pro reo applies. Finally, we might not only subscribe to the principle that we should not punish more than our evidence allows for, but also to the principle that we should not punish more than effectiveness allows for. Not to punish ineffectively, i.e. with harsher than necessary methods to achieve the desired effect, seems like a general condition for the legitimacy of punishment. Ineffective punishment certainly is not justified by the developmental rationale of responsibilization. ${ }^{22}$ But it is precisely the increased amount of evidence we possess for agents complying with the intuitive responsibilization threshold which allows us to punish more effectively. This is what underlies this threshold's practical robustness as outlined above.

Thus, while there are no general normative considerations which would lead us to straightforwardly reject a lowered threshold as acceptable, there are downsides which speak against lowering the intuitive responsibilization threshold to the minimum threshold. In working with the minimum threshold, we lose some robustness of the intuitive threshold in terms of permissibility and effectiveness of responsibilization i.e. those desirable factors which quite likely underlie its empirical relevance.

\section{Responsibilizing Corporations}

Given what has been said so far, may we permissibly responsibilize corporations? There can be little doubt that corporations typically fulfil NoRMATIVE JUdGMENTAL CAPABILITY and CAPABILITy of Control. Just like individual agents, corporations are generally speaking capable of developing an understanding of normative considerations as well as acquiring the relevant evidence, and they are capable of having the control required for choosing between the given options. ${ }^{23}$ That is, they typically fulfil ResPonsibilization FITNESS. In addition, they regularly actually face normatively significant choices, as many business decisions have a normative dimension. That is, they fulfil Normative SignifiCANCE. Thus, corporations meet the minimum responsibilization threshold. We may permissibly responsibilize corporations on this basis - albeit within narrow boundaries as regards the measures we legitimately use for responsibilizing them.

(C) Society for Applied Philosophy, 2017 
To give a concrete example, consider the corporation selling drinks again. Let us call it Quenchers, Inc. As mentioned above, Quenchers at some point starts to buy springs to cut production cost and integrate its supply chain. This business decision may plausibly be considered as having a normative dimension, especially if Quenchers turns springs hitherto commonly owned by a community into private property for the first time. ${ }^{24}$

Originally, Quenchers is unaware of this normative dimension of its business strategy. But soon those employees buying the springs are confronted with the protests of locals who demonstrate outside the town hall, accusing the public officer of corruption, and Quenchers of illegitimate appropriation. In line with Quenchers' official 'Stakeholder Management Guideline', which makes reporting complaints from stakeholders (like suppliers and the public) mandatory, the buyers make the board of directors aware of these protests. So, the board of directors debates the normative dimension of Quenchers new business strategy in a meeting and organises a vote on whether Quenchers should stick to it. The board arrives at the conclusion that private ownership of springs actually is desirable, as the advantages of overcoming the inefficiencies commonly owned resources are known to produce outweigh the problems associated to privatising vital goods. Quenchers thus possesses an internal structure of corporate decision making which enables the forming of normative judgments in a meta-language on the group agent level. This board decision is communicated to the buyers. Note that in this case the privatisation of springs is not so much a consequence of the buyers' mental representations and individual goals (although it might be in line with them), but based on the group agent's representational states (as created by the internal reporting mechanisms), its motivational state to become more profitable, and its normative judgment that buying springs is a legitimate way of achieving this goal.

In this example Quenchers at the very least shares the relevant CAPABILITY OF CoNTROL. Following List and Pettit, we may describe Quenchers' supply chain integration strategy as the 'programming cause' for the privatisation of springs, and the individual employee's buying as the respective 'implementing cause'. ${ }^{25}$ List and Pettit's distinction of programming cause and implementing cause is a theory of multi-level causality in which the higher level (the board of directors on the group agent level) 'programs' for what gets 'implemented' on the lower level (the employee on the individual agent level). It allows us to argue against the intuitions that (i) it is only individual agents who can act and who thus exclusively have the relevant CAPABILITY OF CONTROL and that (ii) one and the same action cannot be subject both to the control of the individual and the group agent. '[B] oth programming and implementing are ways ... of being causally relevant and so it makes sense, depending on context, to invoke one or the other in causal explanation of the effect' when asking who controls the action. ${ }^{26}$

Finally, note that in our case both Quenchers and the individual buyers are suitable targets for responsibilization. Both the individual agents and the group agent are capable of having the understanding and access to evidence required for making normative judgments about the options. The former via their personal experience and their individual normative powers of judgment. The latter via its 'Stakeholder Management Guideline' as well as debates and votes in the board meetings. Similarly, both are capable of having the control required for choosing between the options, as the board decision programs for the privatisation of springs which is implemented by the buyers. We may thus hold the group agent responsible without releasing individual agents from their responsibilities. ${ }^{27}$ 
Let us come back to the theoretical argument. Whenever we can show that corporations not only fulfil Normative Judgmental Capability and Capability of Control (like Quenchers does), but also Positive Evidence and Normative Evidence, then we cannot only responsibilize them in principle, but permissibly rely on all those measures we rely on for responsibilizing children - notably the sharp tool of punishment for reinforcing our efforts of responsibilization. In that case, we would profit from the normative and practical robustness of the intuitive threshold. This is important as one might doubt as to how far corporations will change their behaviour in response to mere blame.

Given the functions commercial corporations fulfil in everyday economic life, virtually all corporations can be considered group agents according to List and Pettit's criteria. $^{28}$ They possess representational and motivational states as well as the capacity to intervene suitably in the environment. At the very least those large corporations we typically are most worried about when concerned with deficits of responsibility easily meet these conditions of group agency. As corporations we aim to responsibilize do not appear out of nowhere, we will have experienced them responsibly acting in the positive domain before. For example, whenever they make choices such as how to market their products or how to negotiate labour contracts. Thus, it is rather easy to show that corporations fulfil Positive Evidence.

The case of Normative Evidence is both more important and more complicated. Showing that corporations meet this condition is an epistemic problem. We need to show that the group agent has demonstrated first signs of normative reasoning. But prima facie one might think that not many corporations publicly demonstrate signs of normative reasoning - and thus feel that requiring this condition excludes many corporations from becoming a target of extensive responsibilization. I am not sure, though, that first impression is actually true.

The most obvious counterexample are normative corporate mottos like Google's 'Don't be evil'. Or consider all those slogans used in corporations' advertisements clearly possessing a normative dimension, thus highlighting a basic understanding of the normative aspects of their business. Some advertisements stress how a product is a sustainable or fair alternative or, indeed, how using the product will lead to having a good life. Furthermore, even if a corporation announces, say, in a press release that it endorses the idea that 'the business of business is business (and not morality)' - i.e. if it endorses and adopts the notorious anti-corporate-responsibility slogan - this equally is a normative statement. It is a normative statement in the same way that inaction in a normatively significant situation constitutes a normatively significant choice.

The real problem with showing that corporations meet Normative Evidence is a strategic one. Children naturally let us know once they are able to handle normative reasons. We do not have to incite them to do so. But if corporations are aware that as soon as they demonstrate a certain normative understanding they will become the target of extensive responsibilization, they have an incentive not to let us know that they have such understanding. To give an historical example, a corporation selling cigarettes in the 1960s might have decided that it is in its best interest not to let us know that at some point it became aware that selling cigarettes has a normative dimension.

However, whereas dealing with corporations has the disadvantage of corporations not naturally informing us about their growing normative power of judgment, it has the advantage of us being able to examine the normative reasoning of a group agent 
more extensively than that of children. Generally speaking, there are two different ways to examine the normative reasoning of corporations.

First, we might ask the public relations department of the corporation (or simply a spokesperson) to take a stand as regards a perceived misbehaviour. That is, we might analyse the public or external reasoning of the group agent. This is an easy and noninvasive step. Note that there actually is very little leeway for the corporation to answer to such an inquiry in a way that prevents us from concluding that the corporation has some understanding of the normative issues at stake, if we really are dealing with a normatively significant choice situation. A simple press release stating 'Quenchers, Inc. does not consider the privatisation of springs to have normative implications' will not do. This statement has itself a normative character. And it will only provoke further probing. Such probing, however, cannot easily be evaded by corporations; especially if it is public institutions undertaking the inquiry.

Second, we can even access the internal reasoning of the group agent by analysing protocols of meetings, internal emails, etc. Notably for group agents with functionally inexplicit organisational structures featuring feedback mechanisms there is a wealth of internal group reasoning going on that we are able to access from the outside. ${ }^{29}$ This is because much of the deliberation process will be documented in one way or another, or can be accessed by conducting interviews with the relevant individual agents. In the case of Quenchers, these are the feedback reports and the meeting minutes from the board of directors. In contrast to the first way, accessing this internal evidence is a very invasive practice. ${ }^{30}$

If we are combining both ways to examine the normative reasoning of group agents it should be no problem to show that corporations fulfil Normative Evidence. Consider that corporations, just like children, learn by observing and imitating others. No corporation is an island. Corporations make major efforts to understand their environment, to identify opportunities and risk. And if one corporation in a certain industry is in some way reproached with perceived misconduct, then all other corporations in that industry can be expected to also become aware of the normative implications of their actions at the same time. This awareness will be reflected in the internal reasoning of the group agent in some way.

One might doubt whether analysing a corporation's internal reasoning - infringing the group agent's privacy, so to speak - ever is a legitimate practice, given how invasive it is. The answer to this is a clear yes. At least in response to particularly serious misbehaviour, e.g. criminal offenses, there is virtual unanimity that we are allowed to proceed like this. Courts in many countries do so on a regular basis. This is because in such cases there is an overwhelming interest to find out whether the group agent is fit - not only to be responsibilized - but to be held responsible.

Apart from such extreme cases, I think there also are other situations when we may permissibly access the group agent's internal reasoning. In fact, it seems difficult to at the same time hold that responsibilization as such is permissible and deny that there can be cases in which invasive measures are legitimate. We tend to think that responsibilization is justified because of a developmental rationale. That is, we admit that strictly speaking it is inappropriate to blame an agent although he is not fit to be blamed, but we highlight that the good that eventually comes out of such responsibilization justifies this means. Thus, we are putting forward a consequentialist argument. Now, if we are willing to weigh the desirable developmental effects of responsibilization against the inherent misallocation of blame this practice brings, then it seems like 
we should also be comparing the benefits and costs of responsibilization more generally. To be sure, infringing a group agent's privacy is a considerable cost. But we can easily imagine deficits of responsibility intolerable enough to offset this cost. For example, if the analysis of a certain corporation's internal reasoning led to the insight that that corporation, whose business activities seriously harm the health of all of the inhabitants of the town it is based in, is aware of the normative dimension of its activities, and if responsibilizing that company led to drastically reducing this harm, then (even if inflicting that harm is no crime) the invasive measure seems to be warranted based on a consequentialist calculus.

The case in favour of the invasive measure becomes even clearer once we take into account the imitation learning of group agents. If one corporation in a certain industry is being responsibilized based on internal documents, then all other corporations in that industry can be expected to also be aware of the normative implications of their actions. Thus, by infringing one corporation's privacy and responsibilizing it, we are making all other corporations in the same industry likewise meet NoRMATIVE EvidENCE - and thus legitimate targets for beneficial responsibilization. Put differently, the external effects of examining one corporation's internal reasoning are considerable.

I do not want to go further into examining when invasive measures may be legitimate. In the end, each case needs to be judged individually. Suffice it to say that this approach of gaining information of an agent's capacity to handle normative reasons exists and might sometimes be legitimate. Notwithstanding this possibility of escalation, most of the time the non-invasive method will be enough to establish that a corporation fulfils Normative Evidence.

To conclude, we can show that the overwhelming majority of corporations not only fulfils the minimum responsibilization threshold but also the intuitive responsibilization threshold. That they do so certainly is to be expected with respect to those manifest deficits of responsibility linked to a corporation's activities everybody knows about - and on which our efforts of responsibilization naturally focus. So, we may permissibly responsibilize most corporations in a far-reaching way; basically in the same way we responsibilize children. Based on what we know about a corporation fulfilling the intuitive responsibilization threshold, we may employ a mixture of precise, purposeful, and efficient responsibilization techniques - sometimes permissibly reinforced by punishment.

Carl David Mildenberger, Department of Philosophy, University of St. Gallen, Unterer Graben 21, CH-9000, St. Gallen, Switzerland. carldavid.mildenberger@unisg.ch

\section{Acknowledgements}

I would like to thank Verena Rauen for helpful feedback and for giving me the idea for this article.

\section{NOTES}

1 Philip Pettit, 'Responsibility incorporated', Ethics 117,2 (2007): 171-201, at p. 201.

2 Pettit op. cit., p. 176. 
3 Christian List \& Philip Pettit, Group Agency (Oxford: Oxford University Press, 2011), pp. 165-66.

4 I focus on commercial corporations throughout. Notwithstanding this focus, my findings generalize to other group agents. I will build on Pettit's account of corporate responsibility. That is, this article constitutes a development of Pettit's position. As such, it naturally inherits its perceived weaknesses.

5 Hardin and Reiff, for example, think it is undesirable, as holding group agents responsible leads to a freeing of individuals from personal responsibility: Garrett Hardin, 'The tragedy of the commons', Science 162 (1968): 1243-48. Mark Reiff, 'Terrorism, retribution, and collective responsibility', Social Theory and Practice 28,3 (2008): 442-55. We might also be skeptical whether responsibilizing group agents has as enduring effects as responsibilizing individual agents. Probably, to expect a unitary, enduring character in the case of corporations is to expect too much. If so, this would significantly reduce the expected benefits of responsibilization.

6 Pettit op. cit., p. 201.

7 List \& Pettit op. cit., p. 155.

8 Unlike List and Pettit, I am referring to this condition as Normative Judgmental Capacity - for reasons to become apparent below.

9 List \& Pettit op. cit., p. 154. In the following, I adopt List and Pettit's rather narrow understanding of 'normative' as 'moral' which is implicit in their conditions.

10 Pettit op. cit., p. 201.

11 List \& Pettit op. cit., p. 157.

12 List \& Pettit op. cit., p. 20.

13 The positive and normative versions of Relevant control are identical.

14 I am aware that the spaghetti case features a very simple object of responsibility - and that there are significantly more complex objects of responsibility out there. Intuitively, the responsibilization threshold will feature more demanding conditions when complex objects are concerned.

15 On the outstanding importance of reasoning by analogy for human learning, also in the moral domain, see, for example, Gigerenzer's work: Gerd Gigerenzer, 'Moral intuition = fast and frugal heuristics?' in W. Sinnott-Armstrong (ed.) Moral Psychology: Vol 2. The Cognitive Science of Morality: Intuition and Diversity (Cambridge, MA: MIT Press, 2008), pp. 1-26. Gerd Gigerenzer, Peter M. Todd \& the ABC Research Group, Simple Heuristics That Make Us Smart (New York: Oxford University Press, 1999).

16 One might also hold that there is a movement within the normative domain - from first taking into account considerations of, say, prudence, to later considering moral reasons. If one subscribes to this idea, then requiring evidence of prudent choice would constitute a middle ground between the intuitive and the minimum responsibilization threshold.

17 List \& Pettit op. cit., pp. 26-27, 63-64.

18 Because Normative Significance cannot be lowered to the level of Potential Occasion, we find again that the conditions for responsibilizability and for responsibilization are not identical.

19 List \& Pettit op. cit., p. 154.

20 Compare Brennan \& Pettit: Geoffrey Brennan \& Philip Pettit, The Economy of Esteem: An Essay on Civil and Political Society (Oxford: Oxford University Press, 2004). Also see List \& Pettit op. cit, pp. 156-57.

21 To establish the minimum responsibilization threshold I focused on arguments for permissibly weakening Positive Evidence and/or Normative Evidence. This is not to deny that, for example, there are arguments for Normative Evidence already being too weak a condition for legitimizing just any kind of responsibilization. One might, for instance, argue that demonstrating normative judgment in one domain is not enough for allowing responsibilization in a different domain, as this would be asking too much of an agent - possibly wrongfully so.

22 For both individual and group agents there seems to be an absolute lower threshold for effective responsibilization - namely the responsibilizability threshold.

23 List \& Pettit op. cit., pp. 158-63.

24 Jeremy Waldron, The Right to Private Property (Oxford: Clarendon Press, 1990).

25 List \& Pettit op. cit., pp. 159-63.

26 List \& Pettit op. cit., p. 162.

27 List \& Pettit op. cit., pp. 163-69.

28 List \& Pettit op. cit., pp. 19-41.

29 List \& Pettit op. cit., pp. 60-64.

30 Both ways aim at examining the normative understanding of a corporation as regards past behavior. But we can use the findings thus produced for future decisions about responsibilizing the corporation. 
